\title{
A PSicopedagogia NA (RE)INSERÇÃO ESCOLAR DE CRIANÇAS E ADOLESCENTES COM LEUCEMIA
}

\author{
Maria Luiza Mallmann; Rosely Maria Danin Souza; Maria Luiza Rheingantz Becker \\ DOI: $10.51207 / 2179-4057.20210006$
}

\begin{abstract}
RESUMO - Este artigo apresenta um ensaio teórico sobre (re)inserção escolar de crianças com leucemia, sob a perspectiva teórica da Epistemologia Genética de Jean Piaget, a respeito de caminhos possíveis para a atuação da Psicopedagogia. Destacamos da teoria as trocas sociais entre pares, nas quais estão presentes o respeito mútuo, a colaboração, a cooperação e a solidariedade, por serem fatores essenciais para o desenvolvimento intelectual, afetivo e moral do aluno. Trata-se de uma Revisão de Literatura, baseada em Yin e Triviños, na qual analisamos 23 publicações, nacionais e internacionais, publicadas entre 1998 e 2020, que abordam diferentes aspectos da (re)inserção escolar de crianças com leucemia. O artigo traz contribuições sobre o papel socializador da escola e a importância da (re) inserção para os pacientes diagnosticados com leucemia. O resultado deste ensaio teórico aponta possíveis caminhos para a atuação do psicopedagogo no acompanhamento do processo de aprendizagem e como interlocutor da tríade equipe de saúde-família-escola
\end{abstract}

UNITERMOS: (Re)inserção Escolar. Alunos com Leucemia. Psicopedagogia. Epistemologia Genética.

Maria Luiza Mallmann - Mestranda em Educação Universidade Federal do Rio Grande do Sul (UFRGS); psicopedagoga voluntária no ICI (Instituto Do Câncer Infantil/RS), Porto Alegre, RS, Brasil.

Rosely Danin - Mestranda em Educação - Universidade Federal do Rio Grande do Sul (UFRGS), Porto Alegre, RS, Brasil.

Maria Luiza Rheingantz Becker - Doutora em Educação - Universidade Federal do Rio Grande do Sul (UFRGS); professora - FACED, PPGEdu/UFRGS, Porto Alegre, RS, Brasil.
Correspondência

Maria Luiza Mallmann

R. Uruguai, 240 conj. 102 - Porto Alegre, RS, BrasilCEP 90010-140

E-mail: mallmann.ml@gmail.com 


\section{INTRODUÇÃO}

Neste artigo apresentamos um ensaio teórico que foi desencadeado no desenrolar de uma pesquisa sobre o processo de escolarização de crianças e adolescentes com leucemia*. O estudo piloto desta pesquisa suscitou as seguintes questões: a) como a Psicopedagogia pode contribuir para a reinserção escolar de crianças com leucemia; b) qual o seu papel no processo de aprendizagem desses alunos. Para responder a estas questões, realizamos uma revisão de literatura em artigos científicos e livros, num total de 23 publicações nacionais e internacionais.

Para Yin ${ }^{1}$, a revisão de literatura propicia encontrar outros estudos com temas semelhantes, o que corrobora com a afirmação de Triviños ${ }^{2}$ de que a revisão literatura permite ao pesquisador "aumentar sua experiência em torno de determinado problema". No primeiro momento a revisão foi realizada de modo abrangente usando como palavras-chave: câncer infantil, inserção escolar, leucemia, crianças e adolescentes.

A partir dessa busca preliminar, desenvolvemos a segunda etapa usando a forma seletiva, e procurando apenas as publicações que abordassem o papel da Psicopedagogia no contexto da (re)inserção escolar. Este procedimento permitiu-nos detectar a escassez de informações sobre o papel do psicopedagogo no contexto apresentado. Entendemos como relevante desenvolver e aprofundar este estudo.

Tomamos como ponto de partida para o referido aprofundamento o referencial teórico da Epistemologia Genética de Jean Piaget, com o intuito de apresentar pressupostos possíveis para a Psicopedagogia, quando na interface entre equipe de saúde, equipe escolar e família no que se refere à (re)inserção escolar e ao processo de aprendizagem de crianças com leucemia. Abordaremos questões específicas da leucemia na idade escolar.

* A pesquisa "O processo de escolarização de crianças e adolescentes com leucemia" faz parte do projeto de Mestrado de Maria Luiza Mallmann no PPGEdu/UFRGS sob orientação da Profa. Dra. Maria Luiza R. Becker.
A Psicopedagogia, na proposta que desenhamos, está voltada para os casos de pacientes de câncer infantil, em especial de leucemia, que não são atendidos pela Classe Hospitalar - o suporte pedagógico especializado destinado a pacientes infantis hospitalizados impossibilitados de frequentar a escola regular. Existe um número expressivo de pacientes de leucemia, que, após o período de internação, continuam o tratamento em ambulatório ou no próprio domicílio. Eles têm direito ao ensino domiciliar, como consta no documento Classe Hospitalar e Atendimento Pedagógico Domiciliar elaborado pela Secretaria de Educação Especial (SEESP) ${ }^{3}$ do Ministério da Educação.

Porém, faltam dados públicos a respeito dos atendimentos pedagógicos domiciliares, mas com a experiência de atendimento em Organização não Governamental (ONG), pudemos constatar que muitos pacientes infantojuvenis não são atendidos por essa modalidade de ensino. Sendo assim, essas crianças e adolescentes não estão nem na Classe Hospitalar, nem na escola. São esses pacientes, uma vez não atendidos, que necessitam de um olhar cuidadoso e ação efetiva na sua (re)inserção escolar.

É nesse contexto que os profissionais da Psicopedagogia, que atuam em ONGs, nas quais também assistem a pacientes de leucemia, cumprem o que o código de ética profissional preconiza sobre a manutenção do vínculo com a aprendizagem. Realizam o atendimento psicopedagógico e fazem o acompanhamento do processo de (re)inserção escolar.

As crianças e adolescentes que passam por uma doença grave como a leucemia enfrentam o estigma do câncer que ainda persiste na sociedade - a iminência da morte. Mas, como as estatísticas apontam, a sobrevivência tem aumentado, assim sendo, esses pacientes retornam à normalidade da vida, podendo participar de passeios, festas, encontros com os amigos e familiares e volta à escola. Porém, enfrentam outros desafios, por exemplo, a superproteção da família e a rejeição social devido a sua aparência física, que pode incluir: perda de peso, alopecia e palidez, o que interfere diretamente 
na sua autoestima, e muitas vezes produz um efeito deletério no seu desenvolvimento.

O ser humano, ao nascer, diferentemente de outros animais, necessita aprender a falar, a andar, entre outras aprendizagens necessárias para a sua sobrevivência. Aprendemos pela interação com os objetos de conhecimento e pela inter-relação com os outros. Os conhecimentos acumulados pelas gerações anteriores são transmitidos socialmente, a escola é o espaço educacional eleito pela sociedade para esse fim, sendo a linguagem, a escrita, a numeração e os regramentos sociais alguns destes conhecimentos. Assim, ela pode ser definida como um lugar de aquisição de conhecimentos e de socialização.

Jean Piaget, mesmo não sendo educador, como ele mesmo afirmava, contribuiu com seus estudos para a valorização da escola e para o conhecimento sobre os processos de aprendizagem. Ao referir-se ao direito à educação para todas as pessoas, reconheceu "o papel indispensável dos fatores sociais na própria formação do indivíduo" 4 . E no decorrer de seus estudos e pesquisas evidencia que as trocas sociais entre pares são essenciais para o desenvolvimento da afetividade, da intelectualidade e da moral, considerando o respeito, a colaboração, a cooperação e a solidariedade como sentimentos e valores fundamentais para o desenvolvimento pleno do aluno.

Considerando o contexto das crianças e adolescentes, neste estudo faz-se necessário retomar algumas especificidades sobre a leucemia e o processo de escolarização durante seu tratamento. A seguir, com os achados selecionados em nossa revisão de literatura, abordamos o tempo hospitalar e o tempo escolar; a equipe de saúde, família e equipe escolar, como uma inter-relação necessária; o caminho da Psicopedagogia sob a perspectiva teórica de Jean Piaget; e, para finalizarmos, apresentamos a discussão e considerações finais.

\section{LEUCEMIA E O PROCESSO DE ESCOLA- RIZAÇÃO}

A leucemia é uma doença maligna dos glóbulos brancos, geralmente de origem desconhecida, que acomete pessoas de todas as faixas etárias, incluindo crianças e adolescentes. Tem como principal característica o acúmulo de células doentes na medula óssea, que substituem as células sanguíneas normais. De acordo com Di Napoli5 ${ }^{5}$ a maior incidência das leucemias é até os 10 anos de idade, sendo a faixa de maior incidência entre 2 e 5 anos, porém, dificilmente surge abaixo dos 2 anos e após os 10.

Segundo informações do Instituto Nacional do Câncer (INCA) ${ }^{6}$, o câncer infantil é a doença com maior índice de óbitos entre crianças e adolescentes no Brasil (Tabela 1).

A sobrevida estimada, por esta doença, na faixa etária de zero a 19 anos, é de $64 \%$. Este índice é calculado com base nas informações de incidência e mortalidade informadas nos Registros de Câncer de Base Populacional e do Sistema de Informações sobre Mortalidade. Salientamos que os índices de cura em torno de 70 a $80 \%$ são as estimativas nos grandes centros internacionais, e, também, são alcançados nos grandes centros brasileiros ${ }^{6}$. A diferença entre esses índices tem relação com a distância dos centros para tratamento e demora do diagnóstico, que podem ser considerados como decorrentes da situação socioeconômica da população.

Superada a fase de tratamento intensivo e observando-se melhoras do paciente, é hora de retomar contato com a realidade do cotidiano, que inclui a escola. As crianças e adolescentes com leucemia, ao retornarem à escola, deparam-se com a defasagem escolar, como

\begin{tabular}{|l|c|}
\hline \multicolumn{2}{|c|}{$\begin{array}{c}\text { Tabela } 1 \text { - Percentual da Incidência } \\
\text { do Câncer Infantil }\end{array}$} \\
\hline Tipo & Percentual \\
\hline Leucemias & $26 \%$ \\
\hline Linfomas & $14 \%$ \\
\hline $\begin{array}{l}\text { Tumores do sistema nervoso central } \\
\text { (SNC) }\end{array}$ & $13 \%$ \\
\hline Outros & $47 \%$ \\
\hline Fonte: elaborado pelas autoras \\
\hline
\end{tabular}


consequência das muitas faltas ao longo do período letivo, devido a internações, consultas, exames e indisposição causada pelos medicamentos, como por exemplo, fadiga e náusea.

Estes aspectos, defasagem escolar e absenteísmo decorrentes da leucemia, necessitam de pesquisas com o intuito de verificar suas consequências em termos de progressão escolar dos alunos-pacientes. No Brasil não há dados estatísticos públicos que mostrem a abstenção escolar por motivo de doença grave ou crônica.

Em levantamento realizado por uma das autoras deste artigo sobre pesquisas relacionadas ao processo de escolarização de crianças e adolescentes, diagnosticadas com câncer infantil, verificamos que também há poucas pesquisas no Brasil. São significativas para este estudo as pesquisas realizadas por Covic et al. ${ }^{8,9}$.

Estas pesquisas foram realizadas em um hospital do estado de São Paulo que é considerado como um centro de referência para o tratamento de câncer infantil. A pesquisa de $2004^{8}$ teve como população alvo pacientes oncológicos, entre eles alguns em tratamento de leucemia; na de $2017^{9}$ a população estudada foi de pacientes oncológicos submetidos a transplante de células hematopoiéticas (TCH).

Na primeira pesquisa Covic et al. ${ }^{8}$ abordam a frequência escolar dos pacientes em tratamento oncológico, e apresentam dados sobre a abstenção escolar, em que a principal justificativa (71\% dos casos) é a decisão dos pais e do agente escolar de que o aluno-paciente só volte à escola após o término do tratamento. Os pesquisadores apontam como um fator que desfavorece o processo de escolarização a "falta de uma comunidade escolar preparada para a inclusão de alunos em situação especial de aprendizagem" ${ }^{8}$. Tais resultados indicam o despreparo dos pais e agentes escolares em relação às reais necessidades desses alunos-pacientes de forma que possam contribuir para o seu desenvolvimento.

A segunda pesquisa de Covic et al. ${ }^{9}$ contribuiu para o estudo que ora apresentamos por ter sido uma investigação longitudinal entre 2000-2015 que realizou o acompanhamento da população estudada, e que demonstra o entendimento do processo de escolarização irregular pelo qual passam os alunos-pacientes oncológicos submetidos ao transplante de células hematopoiéticas (TCH). Segundo dados dessa pesquisa, em média, o afastamento escolar durante o tratamento de leucemia pode chegar a 360 dias, o que equivale a um longo tempo de afastamento, que pode ter sérias consequências no desenvolvimento e na aprendizagem do aluno-paciente.

\section{O TEMPO HOSPITALAR E O TEMPO ES- COLAR}

A dificuldade na (re)inserção escolar de aluno-paciente com doença grave ou crônica está relacionada ao seu afastamento decorrente de uma internação hospitalar prolongada ou por curto período. Quando volta para casa, precisa realizar frequentes consultas médicas e exames, como também pode precisar manter-se em casa por algum período.

Na transição entre o tratamento hospitalar e a frequência na escola, ou seja, entre os diferentes "tempos", o hospitalar (tratamento) e o escolar, o paciente não está mais hospitalizado, mas continua seu tratamento, passando a ser aluno-paciente; sua escolarização, por isso, carece de acompanhamento cuidadoso no sentido de desenvolver suas potencialidades e dar prosseguimento ao seu processo educacional de modo a não levá-lo ao abandono escolar.

Para Ceccim ${ }^{10}$, a classe hospitalar tem um papel coadjuvante na inserção escolar, pois é a classe hospitalar que mediará o tempo hospitalar e o tempo escolar. Nessa transição entre hospital/escola Ceccim ${ }^{10}$ e Ortiz \& Freitas ${ }^{11}$ trazem para o debate a questão da (re)inserção escolar como a "normalização" da vida, que deveria ser uma experiência positiva por favorecer a conexão com a possibilidade do aprender.

Em pesquisa a respeito da incidência de impasses escolares (falta, repetência, fracasso escolar) em crianças adoecidas pelo câncer, Cohen \& Melo ${ }^{12}$ analisaram os aspectos psíquicos envolvidos no adoecimento orgânico e sua 
relação com a escola. Neste estudo, em que a pergunta central é: "O que representa a escola/ educação para cada sujeito, no momento do adoecimento e ou ao longo do tratamento?", as autoras propõem uma reflexão para entender a relação aluno-paciente/escolarização. Esta reflexão é rica ao fazer referências importantes quanto à função do desejo de aprender e ao papel da classe hospitalar como uma ligação com a vida, uma vez que traz para o hospital a escola, e desta forma a possibilidade de continuar aprendendo.

O estudo realizado por Mendes et al. ${ }^{13}$, em hospital na cidade de Salvador, proporcionou a compreensão da realidade e esclarecimento das múltiplas dimensões do fenômeno complexo que é o tratamento oncológico para crianças e adolescentes. Verificaram que os pacientes entrevistados verbalizaram "dificuldades de ordens clínica e psicológica, tais como os efeitos colaterais do tratamento clínico, mudança de rotina e impossibilidade de frequentar a escola formal" ${ }^{13}$.

Na percepção dos autores, para os adolescentes a interrupção escolar é mais difícil devido à proximidade do ingresso no ensino superior e do mercado de trabalho. Além de ser uma fase importante do ciclo vital, quando passam por transformações e estão construindo sua identidade e o pertencimento ao grupo social é essencial. Os autores acreditam que a classe hospitalar é uma maneira possível e adequada de atender às necessidades de escolarização dos pacientes oncológicos em internação.

Para as crianças, o afastamento escolar significa muito mais do que um simples prejuízo educacional, como afirmam Gonçalves \& Valle ${ }^{14}$. Pode significar um período no qual a criança sente-se sozinha, e esta solidão, associada a outros fatores que envolvem o tratamento, pode torná-lo ainda mais difícil. As autoras apontam que no processo de inclusão escolar destas crianças é necessário que se estabeleça uma comunicação colaborativa entre equipe de saúde e escola. Ressaltam que hospital-família-escola devem formar uma aliança fundamental para a manutenção do processo escolar.
Os dados evidenciados nas pesquisas apresentadas são fontes de informação para o preparo da classe hospitalar e equipe escolar, para que saibam lidar com esse aluno-paciente e para que possam lhe favorecer uma melhor adaptação a esse momento e circunstâncias de estar na escola.

\section{EQUIPE DE SAÚDE, FAMÍLIA E EQUIPE ESCOLAR - UMA INTER-RELAÇÃO NE- CESSÁRIA}

Como afirma Nascimento ${ }^{15}$, o psicopedagogo na equipe de saúde multidisciplinar, ao atuar "com o desenvolvimento integral desse paciente e com a manutenção de sua aprendizagem [...], possibilitará sua reinserção na vida escolar [...]. Seu papel é também o de locutor nas relações interpessoais da escuta à criança e à sua família, bem como aos profissionais da equipe, através de uma atuação que favoreça o atendimento em uma visão integrada biopsicossocial em saúde" ${ }^{15}$.

No atendimento hospitalar aos pacientes de câncer infantil, além da classe hospitalar, quando existente, e a equipe médica, há outros profissionais da área da saúde, entre eles psicólogos, assistentes sociais e enfermeiros, que também atuam positivamente na (re)inserção escolar.

Essa forma de atuação está colocada em diversas pesquisas, entre as quais destacamos as que seguem. Moreira ${ }^{16}$ aborda o papel da equipe de saúde, em especial o papel do psicólogo, na tarefa de preparar os professores para receber o aluno-paciente no retorno à escola. Silveira \& Custódio ${ }^{17}$ realizaram estudos com o objetivo de conhecer os aspectos fundamentais do processo de reinserção escolar das crianças com câncer e o papel do assistente social nesta realidade. Camara ${ }^{18}$ destaca o papel da equipe de enfermagem e profissionais da saúde no suporte aos pacientes no processo de inserção escolar, no que diz respeito ao auxílio à compreensão das suas necessidades de cuidados e como respondem a demanda do retorno à escola, objetivando um planejamento da assistência qualificada no âmbito hospitalar. 
No ensaio apresentado por Paterlini \& Boemer ${ }^{19}$, as autoras abordaram a reinserção escolar, do ponto de vista da enfermagem, apontando os avanços conquistados e as perspectivas futuras. Analisaram as dificuldades enfrentadas pela criança com câncer na reinserção escolar, estando, entre elas, o temor dos pais, o despreparo dos professores e o enfrentamento do olhar dos colegas decorrente das diferenças físicas. Para as autoras, a legislação brasileira necessita incluir parágrafos específicos sobre a manutenção da escolaridade desses pacientes. Como avanços, apresentam o trabalho de escolarização realizado pelas classes hospitalares no estado de São Paulo.

O estudo de Silva ${ }^{20}$ apresenta como resultado os aspectos positivos sobre o cotidiano escolar das crianças doentes: a socialização, o desenvolvimento acadêmico e pessoal; e aspectos negativos: as faltas e a hostilização sofrida em virtude dos efeitos colaterais da doença. Esta pesquisa indica a possibilidade de o profissional da Psicopedagogia ser o elemento que contribui para a superação dos aspectos negativos e com o processo de escolarização, que abrange a aprendizagem e a socialização, como já foi visto.

A equipe de saúde, como demonstrado nas pesquisas trazidas nesta análise, é de fundamental importância no que diz respeito ao acompanhamento e suporte emocional à criança acometida pela leucemia. É também necessária como orientadora dos familiares e da equipe escolar, para que estes sejam preparados para contribuírem para a "normalização da vida" do aluno-paciente, incluindo a (re)inserção escolar.

No contexto apresentado, a família do paciente com leucemia é afetada, pois o período do tratamento exige alteração na rotina familiar, se considerarmos que a internação interrompe a atividade profissional dos pais, altera a relação de proximidade dos irmãos e da família extensa. Além disso, quando o paciente retorna para casa é preciso manter as idas regulares ao médico, os exames clínicos, e a necessidade de administração da medicação. Tudo isso exige um desprendimento de energia muito grande de todos. Estes fatores são motivos para muitos pais ou responsáveis adiarem o retorno para a escola

Por outro lado, o retorno às atividades escolares pode ser um fator estressante se a criança ou adolescente sentirem que não há compreensão de sua condição, fazendo com que a família, por medo de expor seu(sua) filho(a), o afaste da escola. E, ainda, as expectativas da família se juntam às expectativas dos colegas e professores com relação ao retorno à escola, sendo este um aspecto que merece mais atenção, porque estes "atores" têm papel importante na (re) inserção escolar. Depende deles o como o aluno-paciente será reconhecido, se será visto como um ser frágil que nada pode, se como apenas um corpo no espaço sem reconhecimento de suas potencialidades e peculiaridades, ou como alguém capaz de aprender e se relacionar positivamente com seus pares e professores, apesar de suas fragilidades.

A continuidade da escolarização para ser exitosa, para o aluno e escola, também depende das condições educacionais e econômicas da família, porque tais condições estão diretamente relacionadas às expectativas que os pais têm em relação ao futuro de seu filho e o significado do estudo para cada família.

Quanto menos escolarizada a família, e quanto menor o poder aquisitivo, menor são suas expectativas em relação à continuidade da escolarização do filho adoecido. Esse é um grande desafio a ser enfrentado no processo de escolarização de pacientes de leucemia quando consideramos seu meio social. Porém, esta questão não está sendo foco de análise neste artigo.

Como pode ser constatado, há evidências de que é fundamental que familiares sejam conscientizados da necessidade de o aluno-paciente retornar à escola o mais breve possível, e que este receba o apoio necessário para o enfrentamento das dificuldades decorrentes de sua condição de adoecimento.

Diante de tais aspectos apresentados, insistimos na importância da escola que, segundo Del$\mathrm{val}^{21}$, tem importante papel na nossa sociedade 
por contribuir para a socialização das crianças através de suas relações com os colegas, adultos, e, especialmente, com os professores.

O autor coloca que é atribuída, cada vez mais, uma maior importância ao papel das relações com os pares no desenvolvimento da criança, o que corrobora o que Piaget já apresentava em seus estudos desde a década de 1930, e que demonstra em sua obra O Juízo Moral na criança ${ }^{22}$, lançado em 1932, e que é reafirmado em outras obras, como por exemplo: Jean Piaget: Sobre a pedagogia - textos inédito ${ }^{23}$ e Relações entre a afetividade e a inteligência no desenvolvimento mental da criança ${ }^{24}$.

Portanto, consideramos que tal posicionamento sinaliza que a escolarização para o aluno-paciente é indiscutivelmente necessária para o seu desenvolvimento. Para refletirmos sobre tal premissa, apresentamos algumas das pesquisas selecionadas que reforçam a importância da escolarização dessas crianças ou adolescentes. Como, também, aspectos que precisam ser considerados nesse processo e que envolvem a equipe escolar, especialmente os professores, na relação e atendimento ao aluno-paciente.

Sendo o professor o principal agente da (re)inserção escolar, trazemos a pesquisa de Carvalho ${ }^{25}$, que mostra a perspectiva do professor que tem aluno adoecido. Como resultado importante deste estudo, a autora afirma que a psicanálise propiciou a compreensão teórica para “esclarecer o impacto do câncer da criança na subjetividade do professor" 25 .

E complementa esta ideia dizendo que é preciso prover meios para informar o professor sobre o câncer e criar condições para o enfrentamento deste professor frente ao impacto subjetivo, que é ter um aluno com câncer infantil, para que então possa vir a ser um agente da inserção escolar do aluno-paciente. Em seu estudo ainda sugere a necessidade de pesquisas quantitativas para verificar como está a frequência escolar dos pacientes de câncer infantil, pois a recomendação é que o aluno-paciente mantenha a escolarização, afastando-se somente durante períodos críticos, como preconizam as sociedades de oncologia pediátrica.

A pesquisa realizada por $\mathrm{NuCci}^{26} \mathrm{Com}$ professores que tiveram aluno com leucemia envolveu uma reflexão sobre a experiência vivenciada, através de perguntas sobre o conhecimento que tinham sobre a doença, como os professores viam seu aluno-paciente e avaliavam sua prática profissional nesse contexto. Esta pesquisa envolveu 129 sujeitos de diversos estados brasileiros.

No resultado $\mathrm{Nucci}^{26}$ elenca vários sentimentos apontados pelos professores, mostrando um envolvimento emocional acentuado. A autora traz em suas conclusões a importância de um trabalho preparatório com a equipe escolar, em especial com o professor - que receberá esse aluno-paciente de leucemia - para que este possa colaborar no desenvolvimento de suas potencialidades, de forma a garantir o direito à educação a esse aluno.

Encontramos no estudo de Rocha ${ }^{27}$ a história de Roberto, rapaz que esteve em tratamento de câncer na adolescência, sofreu a amputação de uma perna e mostra como enfrentou a mutilação e construiu sua identidade emancipatória.

Tal caso, considerado emblemático, é apresentado por Rocha \& Antunes ${ }^{28}$ separadamente e em 2012 compôs um artigo publicado. As autoras, em suas conclusões, declaram que o retorno à escola do aluno mutilado não é um processo de simples adaptação ou integração escolar. Como afirmam, a escola precisaria "tirar o foco das impossibilidades e investir nas potencialidades" sendo isto, provavelmente, a fórmula para o sucesso na (re)inserção escolar ${ }^{28}$.

Para que isto seja possível, é necessário que a escola conheça esse aluno-paciente que retorna, para que possa auxiliá-lo, tendo em vista que na rotina desta criança ou adolescente estão incorporadas as idas às consultas e exames como parte de sua nova condição.

Encontramos nas pesquisas internacionais realizadas por Pini et al. ${ }^{29}$, no Reino Unido; Thompson et $\mathrm{al}^{30}{ }^{30}$, nos EUA; e Helms et al. ${ }^{31}$, 
na Dinamarca, convergências no estudo sobre o impacto do diagnóstico de câncer no processo de escolarização. Essas pesquisas apontam que o sucesso da (re)inserção escolar de crianças e adolescentes está relacionado com o serviço de apoio aos educadores e familiares dos pacientes, assim como a necessária informação dada aos colegas de aula, seus pares. Desta forma, acreditam que isso estimule a frequência escolar.

O trabalho desenvolvido por Oliveira ${ }^{32}$, no qual analisou as vivências escolares de um grupo de seis adolescentes e jovens adultos sobreviventes de câncer, corrobora com os estudos acima relacionados quando diz que a articulação otimizada entre família-escola-hospital é fundamental na conquista da continuidade do processo de escolarização. A autora aponta como destaque a importante função no ajustamento psicossocial da criança e adolescente pacientes de câncer.

Neste sentido é urgente que sejam implementadas estratégias e métodos que facilitem a continuidade da escolarização ao longo da doença. A autora afirma que se faz necessário dar voz aos principais protagonistas, crianças e adolescentes com doença oncológica, na busca de soluções que "verdadeiramente se ajustem às suas necessidades de bem-estar físico, motivação, autoestima e, entre outros, relações sociais gratificantes e saudáveis" 32 .

Em suma, a escola, especialmente os professores ao estarem informados sobre as condições de saúde do aluno-paciente e sobre o andamento de seu tratamento, pode contribuir da melhor forma com o processo de aprendizagem e desenvolvimento desse aluno. Como já foi dito, é preciso investir nas potencialidades existentes, as quais, na maioria das vezes, não diferem das demais crianças.

Em relação aos colegas de aula, o conhecimento sobre o câncer diminui o medo, a rejeição e estimula atitudes mais positivas com relação às crianças e adolescentes diagnosticados, o que favorece o relacionamento com seus pares, e, principalmente, no caso dos adolescentes, provoca efeitos positivos na educação e no emprego.

\section{UM CAMINHO PARA A PSICOPEDA- GOGIA SOB A PERSPECTIVA TEÓRICA DE JEAN PIAGET}

O campo de atuação da Psicopedagogia, como consta no código de ética, está entre a Educação e Saúde, ou seja, o profissional desta área se ocupa "do processo de aprendizagem considerando os sujeitos e sistemas, a família, a escola, a sociedade e o contexto social, histórico e cultural". A intervenção psicopedagógica é da ordem do conhecimento e está relacionada com a aprendizagem, "considerando o caráter indissociável entre os processos de aprendizagem e as dificuldades, as possibilidades dos sujeitos e sistemas" ${ }^{33}$.

Ao pensarmos em construir possíveis ${ }^{34} 4 \mathrm{Ca}-$ minhos para a Psicopedagogia, é preciso uma reflexão sobre o que consideramos como o necessário $^{35}$. A realidade apresentada é daqueles pacientes diagnosticados com leucemia que não estão internados e retornam ou ingressam na escola. Nestas circunstâncias, há necessidade da atuação do psicopedagogo que faça a interlocução entre equipe de saúde-família-escola com o objetivo de agir preventivamente ao rompimento do vínculo com a aprendizagem do aluno-paciente em processo de (re)inserção escolar.

Os possíveis caminhos para a atuação psicopedagógica tornam-se evidentes com o conhecimento da realidade que envolve o tratamento oncológico, os fatores psicológicos e biológicos intervenientes, e as necessidades elencadas a partir da aprendizagem construída pelo profissional.

f Para Piaget, o possível é "o produto de uma construção do sujeito, em interação com as propriedades do objeto, [...] inserindo-as em interpretações devidas às atividades do sujeito, atividades essas que determinam, simultaneamente, a abertura de possíveis cada vez mais numerosos, cujas interpretações são cada vez mais ricas" ${ }^{34}$.

‡ Segundo Piaget, “a necessidade depende das composições realizadas pelo sujeito [...] que resulta de um processo de necessitação e que é solidária com a constituição dos possíveis, este engendrando diferenciações ao passo que a necessidade está ligada às integrações, donde uma equilibração dessas duas formações" ${ }^{35}$ 
Nos estudos e pesquisas realizadas por Piaget o foco estava na investigação do desenvolvimento do conhecimento, como foi demonstrado através dos experimentos, nos quais os comportamentos e desempenho de êxito e fracasso das crianças nas tarefas foram observados. Quando pensamos a atuação psicopedagógica pela teoria de Piaget, podemos analisar as transformações de conduta observando como elas emergem e evoluem.

Por estar no campo da educação, o profissional psicopedagogo, ao ter seu foco no processo de construção do conhecimento, tem possibilidades de compreender como o sujeito aprende, de intervir preventivamente e contribuir para o desenvolvimento da aprendizagem do aluno-paciente. Sua atuação está na ordem da afetividade, que envolve despertar o interesse para o aprender, para o trabalho colaborativo e para o desenvolvimento socioafetivo através das relações sociais na escola.

Segundo Piaget ${ }^{36}$, conhecer resulta das trocas entre o sujeito e o meio, e das ações do sujeito sobre o objeto. Tais ações são responsáveis pela construção do conhecimento. Piaget ${ }^{36}$ afirma que o desenvolvimento da inteligência é decorrente de quatro fatores: a) a maturação, que está relacionada ao desenvolvimento biológico do sistema nervoso; b) as transmissões sociais; c) as experiências físicas e lógico-matemáticas, que correspondem às ações dos sujeitos sobre os objetos; $d$ ) e a equilibração - processo de auto-organização ou autorregulação -, este último funciona como um "mecanismo de autocorreção dos erros que tende a estabelecer o equilíbrio cognitivo" ${ }^{37}$. O autor também diferencia aprendizagem de desenvolvimento, considerando que para a aprendizagem ocorrer é necessário o desenvolvimento de esquemas ${ }^{37} \mp$ e estruturas ${ }^{37} \mathbb{I}$ mentais prévias.

$\S$ esquemas - " $[\ldots]$ aquilo que, em uma ação, é $[\ldots]$ transponível, generalizável, ou diferencial de uma situação à seguinte, dito de outro modo, o que há de comum às diversas repetições ou aplicações da mesma ação" 37

II estruturas - "As estruturas humanas não partem do nada e, se toda estrutura é o resultado de uma gênese, é necessário, decididamente, admitir, à vista dos fatos, que uma gênese constitui, sempre a passagem de uma estrutura mais simples a uma estrutura mais complexa" $[\ldots]^{37}$.
Para crianças que enfrentam situações adversas, como a leucemia, é urgente proporcionar experiências de trocas entre meio e sujeito que sejam enriquecedoras para o seu desenvolvimento e aprendizagem e que impliquem em mudanças de comportamento de autoaceitação e autovalorização.

A Psicopedagogia, por atuar no espaço compreendido entre a saúde e a educação, afeta a saúde mental, e nesta questão está incluída a autoestima. Piaget ${ }^{24}$ fala dos sentimentos de superioridade e inferioridade que estão relacionados com o resultado das avaliações dos outros. Esses sentimentos provêm de causas sociais; nesse sentido, o sentimento de inferioridade é "uma resposta dos fracassos às desaprovações, insatisfações ou desvalorizações, provenientes do outro, sendo o sentimento de superioridade, então, o contrário" ${ }^{24}$.

Como referido anteriormente, o aluno-paciente ao retornar para a escola enfrenta as consequências do absenteísmo, além disso, também pode apresentar dificuldades na inter-relação com seus pares. A escola, como um espaço educacional e social, deve preparar-se para acolher esse aluno-paciente. Piaget fala a respeito do "problema psicopedagógico das relações sociais próprias da infância", ao se referir aos modelos de escola, a tradicional e a moderna $^{38}$.

A criança vive uma socialização progressiva e que segue sem fim por toda vida. Na relação com o outro por adaptação gradual, através da assimilação dos outros a si e da própria acomodação ao outro, conquista "duas propriedades essenciais da sociedade exterior: a compreensão mútua baseada na palavra, e a disciplina comum baseada nas normas de reciprocidade" ${ }^{38}$.

Com isto, queremos dizer que o acolhimento ao aluno-paciente, para que se torne eficiente, necessita estar baseado nessas duas propriedades. A ação psicopedagógica situa-se no encaminhamento das informações sobre as possibilidades do aluno-paciente, - condições de saúde física e mental -, para aproximá-lo da sua capacidade de aprender e de se socializar. 
Para Piaget ${ }^{24}$, a afetividade é construída na relação com o outro, através de relações interindividuais que podem ser cognitivas e afetivas. Para haver afeto, é preciso conhecer e ser reconhecido e, para isto, são necessárias trocas entre os pares.

Refletindo sobre a situação de reinserção escolar, estas relações envolvem trocas cognitivas e, também, valores morais, nos quais o incentivo aos trabalhos grupais favorece a cooperação e a reciprocidade. Piaget afirma que "a reciprocidade é o enriquecimento mútuo, mas é muito mais que isso [...] é a coordenação mútua das atitudes e dos pontos de vista, tanto afetivos como cognitivos" 24 .

Como vimos ao longo deste estudo, o aluno-paciente de leucemia passa por um período de sua vida no qual sofre privações da vida social, isto gerando consequências, entre outras, escolares, afetivas e cognitivas. A Psicopedagogia pode ter um papel fundamental na (re)inserção do aluno-paciente, tanto na ação preventiva da dificuldade de aprendizagem, acompanhando desde o início do tratamento, quanto na manutenção do vínculo com a aprendizagem ao promover o bom desempenho da tríade equipe de saúde-família-escola. O bom desempenho dessa tríade está relacionado com o bem-estar da criança ou adolescente em tratamento, que inclui a aceitação da criança e adolescente, em tratamento, pelos pares ao retornar à escola, de modo a facilitar sua inclusão e vínculo com a escola e colegas.

\section{DISCUSSÃO}

O ensaio teórico a que nos propusemos partiu da necessidade de refletirmos e evidenciarmos as atribuições concernentes ao papel do psicopedagogo na reinserção escolar e na aprendizagem de crianças e adolescentes com leucemia.

As pesquisas realizadas, a vivência de uma das autoras em uma ONG, que atende crianças e adolescentes com câncer, e o aporte teórico da epistemologia genética de Piaget, que é corroborada pelas pesquisas que apresentamos no decorrer deste ensaio, permitiu traçar um caminho possível para a atuação do psicopedagogo.

As pesquisas de Covic et al. ${ }^{8,9}, \mathrm{Ceccim}^{10}$, Ortiz \& Freitas ${ }^{11}$, Cohen \& Melo ${ }^{12}$, Mendes et al. ${ }^{13} \mathrm{e}$ Gonçalves \& Valle ${ }^{14}$ abordam os enfrentamentos que dizem respeito à hospitalização e ao tratamento em si, além de todas as questões familiares e sociais, incluindo a escola, e mostram o quanto é fundamental o papel colaborativo dos envolvidos no cuidado dos pacientes infanto-juvenis, sendo eles a equipe de saúde, a família e a equipe escolar, visto que são os responsáveis pelo futuro destas crianças e adolescentes.

Diante de tal responsabilidade, torna-se necessário prepará-los para que busquem meios de promover a continuidade escolar e o retorno à normalidade da vida para estes pacientes acometidos pela leucemia. Essas pesquisas também abordam a importância do apoio aos adolescentes, uma vez que vivem um momento de planejamento do futuro, em que o grupo social tem grande influência na construção de sua identidade.

A ação psicopedagógica, como refere Nascimento $^{15}$, na função de interlocutora ou locutora, do paciente e de sua família, com a colaboração da equipe de saúde envolvida, oportuniza à escola conhecer sobre a doença e tratamento ao qual esse aluno-paciente está submetido. Esta ação dá condições para que o professor possa olhar seu aluno para além do diagnóstico, sem superproteção, mas vendo suas potencialidades para aprender.

Como é apontado nas pesquisas de Covic et al. ${ }^{8,9}$, Carvalho ${ }^{25}$ e de $\mathrm{Nucci}^{26}$, o despreparo da escola para atender o aluno-paciente de leucemia colabora para a abstenção escolar. Salientamos que o vínculo com a aprendizagem, a participação nas atividades escolares, sempre que o tratamento permitir, propicia à criança e ao adolescente adoecido a possibilidade da normalização da vida, promovendo a melhora na autoestima, na aceitação do tratamento e superação de dificuldades no seu processo de escolarização. 
Kanemoto $^{39}$, em seu livro "Implicações do câncer da criança no processo de alfabetização", diz que "os alunos(as) assumem a responsabilidade pelo processo de escolarização quando contam com o apoio da família; a participação da escola de origem é uma ferramenta facilitadora da permanência e da continuidade dos estudos durante o tratamento, e quando atendidos em suas necessidades para a escolarização, os pacientes optam por estudar" 39 .

Vamos encontrar nas pesquisas de Rocha \& Antunes ${ }^{28}$, Pini et al. ${ }^{29}$, Thompson et al. ${ }^{30}{ }_{\text {, Helms }}$ et al. ${ }^{31}$ e Oliveira ${ }^{32}$ a mesma preocupação com o retorno à escola e a necessidade de um serviço de apoio tanto para acompanhar a (re)inserção do aluno-paciente quanto para preparar a família e escola para receber este aluno.

Da mesma forma, salientam que a equipe deve também olhar para os colegas dando o suporte adequado com o intuito de esclarecer sobre a doença, possíveis alterações físicas e emocionais, e, desta forma, promover a melhora na autoestima, na qualidade de vida, o que corrobora com Piaget quando ele ressalta a importância dos sentimentos de superioridade.

As pesquisas de $\mathrm{Ceccim}^{10}$, Cohen \& Melo ${ }^{12}$ e Mendes et al. ${ }^{13}$ salientam a importância da classe-hospitalar na continuidade do processo de escolarização e aprendizagem. É bastante comum, no caso da leucemia, que durante a internação o acompanhamento pela classe hospitalar não dê conta de atuar preventivamente.

Muitas vezes, a internação envolve ou o início do tratamento - período de estresse muito grande que o paciente não quer, ou a família evita a participação nas atividades -; ou, então, são internações breves para atender alguma questão clínica urgente. Portanto, crianças e adolescentes retornam à escola sem a assistência necessária, porque sabemos que o atendimento domiciliar não é uma prática nas escolas públicas, de um modo geral.

Ao apontar a característica multidisciplinar da equipe de saúde, as pesquisas de Moreira ${ }^{16}$, Silveira \& Custódio ${ }^{17}$, Camara ${ }^{18}{ }_{\text {, }}$ Paterlini \& Boemer $^{19}$ e Silva ${ }^{20}$ mostram o quanto é fundamental para a família e o paciente o apoio desta equipe para o retorno à escola, que é importante a normalização da vida, que isto colabora com a adesão ao tratamento. Nascimento ${ }^{15}$, ao falar da equipe de saúde, inclui o psicopedagogo como um profissional necessário, pois sua atuação contribui para uma visão integrada biopsicossocial em saúde.

A possibilidade de a Psicopedagogia atuar dentro de instituições de apoio multidisciplinar a pacientes de câncer infantil poderia contribuir no processo de (re)inserção desses pacientes. De tal forma, torná-los alunos-pacientes em suas escolas, promovendo sua inclusão no contexto escolar, não só no que diz respeito às condições físicas da escola, mas colaborando com a equipe escolar na aproximação com a equipe de saúde e juntamente com a família pensar estratégias para que a criança ou adolescente não rompa o vínculo com o aprender.

Em suma, o psicopedagogo envolvido no atendimento de crianças e/ou adolescentes em tratamento de leucemia compreende que o retorno à escola está relacionado com a qualidade de vida. A Psicopedagogia pode colaborar com a aproximação do aluno-paciente e a aprendizagem quando promove situações nas quais o aluno-paciente tenha a possibilidade de se conectar com o seu desejo de aprender, trazendo benefícios que terão reflexo ao longo de sua vida acadêmica, pessoal e profissional.

O direito à educação é uma prerrogativa que propicia a oportunidade de convivência social e, consequentemente, colabora para a construção das estruturas mentais. Sendo assim, a escola não pode estar à parte da vida, pois correria o risco de ser apenas uma transmissora de conhecimentos. Para Piaget, "a escola fica com boa parte da responsabilidade no que diz respeito ao sucesso final ou ao fracasso do indivíduo, na realização de suas próprias possibilidades e em sua adaptação social" ${ }^{4}$.

\section{CONSIDERAÇÕES FINAIS}

Resumindo, os estudos brasileiros e internacionais afirmam que a escola é o lugar no qual 
as crianças e adolescentes podem vivenciar o sucesso escolar, o sentimento de competência para a superação do adoecimento, portanto, a esperança de recuperar essas experiências positivas.

Piaget contribui para esta reflexão sobre caminhos possíveis para a intervenção psicopedagógica ao valorizar a escola como lugar para a socialização e o aprender. Este autor enfatiza a importância da afetividade no desenvolvimento intelectual e moral, e afirma que a escola é um espaço propício para as relações de respeito mútuo, cooperação, reciprocidade e solidariedade.

Nesta perspectiva, cabe à ação psicopedagógica, ao atingir seu objetivo, evitar a ruptura da vida acadêmica e promover a continuidade da escolarização, durante e após o tratamento. No entanto, o psicopedagogo ainda é pouco requisitado para compor a equipe hospitalar e o espaço escolar. Essa é uma realidade que merece um olhar mais atento dos educadores e legisladores, para que a escola e o aluno-paciente possam contar com a contribuição da Psicopedagogia na (re)inserção escolar.

A Psicopedagogia atuará na atenção aos alunos adoecidos, que abstêm-se das atividades escolares presenciais, tanto no atendimento de possíveis dificuldades de aprendizagem em virtude desse absenteísmo ou quanto às sequelas da doença ou tratamento que possam afetar a aprendizagem. Também devemos destacar a colaboração desse profissional com a equipe escolar ao preparar professores e colegas para o ingresso ou retorno desse aluno, assim como na interface com a família e equipe de saúde envolvida no tratamento dessa criança ou adolescente.

\section{SUMMARY}

The Psychopedagogy in the school re-entry of children and adolescents with leukemia

This article presents a theoretical essay about the school re-entry of children with leukemia under the theoretical perspective of Jean Piaget's Genetic Epistemology regarding the possible paths for performing Psychopedagogy. The importance of social exchange within peers has been highlighted from the theory, in which mutual respect, collaboration, cooperation and solidarity are present, these being essential factors regarding the intellectual, emotional and moral development of the student. It is a Literature Review, based on Yin and Triviños, in which national and international publications between 1998 and 2020 were analyzed, approaching different aspects of the school (re)entry of children with leukemia. The article brings to light contributions on the socializing role the school plays and the importance of this (re)entry of patients who have been diagnosed with leukemia. The result of this theoretical essay points out possible paths for the performance the performance of the psychopedagogue in following the steps of the learning process and as a mediator of the family-health team-school triad.

KEYWORDS: School Re-entry. Students with Leukemia. Psychopedagogy. Genetic Epistemology. 


\section{REFERÊNCIAS}

1. Yin RK. Pesquisa qualitativa do início ao fim. Porto Alegre: Penso; 2016.

2. Triviños ANS. Introdução à pesquisa em Ciências Sociais: a pesquisa qualitativa em Educação. São Paulo: Atlas; 2010.

3. Brasil. Ministério da Educação. Secretaria de Educação Especial. Classe Hospitalar e Atendimento Pedagógico Domiciliar - estratégias e atribuições. Brasília: Ministério da Educação; 2002 [citado 2019 Ago 18]. Disponível em: http://portal.mec.gov.br/seesp/ arquivos/pdf/livro9.pdf

4. Piaget J. Para onde vai a educação. $20^{\mathrm{a}}$ ed. Rio de Janeiro: José Olympio; 2011.

5. Di Napoli FO. Análise do desempenho cognitivo em pacientes pediátricos e juvenis submetidos a tratamento antineoplásico [tese]. Porto Alegre: Universidade Federal do Rio Grande do Sul; 2010. 77 f [citado 2019 Ago 18]. Disponível em: http://hdl.handle. net/10183/19084

6. Brasil. Ministério da Saúde. Instituto Nacional do Câncer (INCA). Sobrevida de pacientes infantojuvenis com câncer é de 64\% no Brasil. Rio de Janeiro: INCA; 2019 [citado 2019 Ago 18]. Disponível em: https:// www.inca.gov.br/noticias/sobrevida-depacientes-infantojuvenis-com-cancer-e-de64-no-brasil

7. Brasil. Ministério da Saúde. Instituto Nacional do Câncer. Leucemia. Rio de Janeiro: INCA; 2018 [citado em 2019 Ago 18]. Disponível em: https://www.inca.gov.br/ tipos-de-cancer/leucemia

8. Covic AN, Petrilli AS, Kanemoto E. A frequência e a matrícula escolar de crianças e adolescentes com câncer. Rev Soc Bras Cancer. 2004;1(1):10-5 [citado 2018 Nov 7]. Disponível em: http://www.cerelepe.faced.ufba.br/arquivos /fotos/107/freqcriancacancercovic.pdf

9. Covic AN, Oliveira FAM, Zecchin VG, Bastos AC. Tecendo relações entre Educação e Saúde: processo de escolarização de alunos gravemente enfermos. Rev Int Humanidades Med. 2015;6(2):1-9 [citado em: 2018 Nov 7]. Disponível em: https://journals.eagora.org/ revMEDICA/article/view/1567

10. Ceccim RB. Classe hospitalar: encontros da educação e saúde no ambiente hospitalar. Pátio. 1999;3(10):41-4 [citado 2018 Jun 13]. Disponível em: http://www. cerelepe. faced.ufba.br/arquivos/fotos/84/ classehospitalarceccimpatio.pdf
11. Ortiz, LCM, Freitas, SN. Considerações acerca da inclusão escolar de crianças pós-hospitalizadas. Cad Educ Espec. 2002;20:1-8 [citado 2020 Set 10]. Disponível em: http://www. cerelepe.faced.ufba.br/arquivos/fotos/53/ inclusaoescolarcriancasposhospitalizadas.pdf

12. Cohen RHP, Melo AGS. Entre o hospital e a escola: o câncer em crianças. Estilos Clín. 2010;15(2):306-25 [citado 2019 Set 18]. Disponível em: http://www.periodicos.usp. br/estic/article/view/46093

13. Mendes MVC, Góes ÂCF, Brain FRM. Crianças e adolescentes em tratamento oncológico: uma análise sobre a visão do adiamento do início ou interrupção da educação escolar. Rev Bras Cancerol. 2018;64(3):301-9 [citado 2019 Ago 8]. Disponível em: https://rbc.inca.gov.br/ revista/index.php/revista/article/view/27

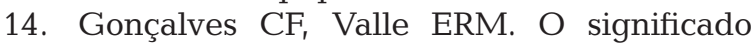
do abandono escolar para a criança com câncer. Acta Oncol Bras. 1999;19(1):273-9 [citado 2018 Abr 28]. Disponível em: http:// bases.bireme.br/cgi-bin/wxislind.exe/iah/ online/?IsisScript=iah/iah.xis\&src=google\& base $=$ ADOLEC \&lang $=p \&$ nextAction $=\operatorname{lnk} \&$ exprSearch=519914\&indexSearch=ID

15. Nascimento CT. A psicopedagogia no contexto hospitalar: quando, como, por quê?. Rev Psicopedag. 2004;21(55):48-56 [citado 2018 Ago 16]. Disponível em: http://www.revista psicopedagogia.com.br/detalhes/300/apsicopedagogia-no-contexto-hospitalar-quando--como--por-que-

16. Moreira GMS. A criança com câncer vivenciando a reinserção escolar: estratégia de atuação do psicólogo [dissertação]. Ribeirão Preto: Universidade de São Paulo; 2002 [citado 2019 Abr 19]. Disponível em: http://www.teses.usp.br/teses/disponiveis/ 59/59137/tde-27082004-145234/

17. Silveira CR, Custódio SAM. A reinserção escolar da criança com câncer e a importância da atuação do Assistente Social frente a esta realidade. RIPE Rev Inst Pesq Estud Construindo Serv Soc. 2006;10(18):1-84 [citado 2018 Nov 15]. Disponível em: http://ojs.ite.edu.br/index.php/css/article/ viewFile/63/111

18. Camara CT. A reinserção escolar de crianças e adolescentes com câncer após o término do tratamento: subsídios para o cuidado de enfermagem. [dissertação]. Ribeirão Preto: Universidade de São Paulo; 2011 [citado 2018 Nov 7]. Disponível em: http://www. 
teses.usp.br/teses/disponiveis/22/22133/ tde-28112011-160557/

19. Paterlini ACCR, Boemer MR. A reinserção escolar na área de oncologia infantil - avanços \& perspectivas. Rev Eletrônica Enferm. 2008;10(4):1152-8 [citado 2019 Maio 29]. Disponível em: https://revistas.ufg.br/fen/ article/view/46824

20. Silva GM. Compreendendo a escolaridade de crianças com câncer: visão de mães, professores e colegas assistidos por um programa de reinserção escolar [tese]. Ribeirão Preto: Universidade de São Paulo; 2006 [citado 2019 Abr 20]. Disponível em: https://repositorio. usp.br/item/001528692

21. Delval J. Crescer e Aprender - a construção do conhecimento na escola. Porto Alegre: Artmed; 1998.

22. Piaget J. O juízo moral na criança. São Paulo: Summus; 1994.

23. Parrat S, Tryphon, orgs. Jean Piaget: Sobre a Pedagogia - textos inéditos. São Paulo: Casa do Psicólogo; 1998.

24. Piaget J. Relações entre afetividade e a inteligência no desenvolvimento mental da criança. Rio de Janeiro: Wak; 2014.

25. Carvalho MEE. A criança com câncer e o professor: contribuições psicanalíticas [dissertação]. São Paulo: Universidade de São Paulo; 2014 [citado 2018 Nov 7]. Disponível em: http://www.teses.usp.br/ teses/disponiveis/47/47133/tde-25032015123840/en.php

26. Nucci NAG. A criança com leucemia vai à escola. Campinas: Livro Pleno; 2002.

27. Rocha MCM. O processo de escolarização do aluno mutilado pelo câncer: a transformação da identidade no processo de inclusão escolar [dissertação]. São Paulo: PUC SP - Pontifícia Universidade Católica de São Paulo; 2009 [citado 2019 Abr 20]. Disponível em: https:// tede.pucsp.br/bitstream/handle/16590/1/ Magna Celi Mendes da Rocha.pdf

28. Rocha MCM, Antunes MAM. Mutilação pelo câncer: articulações entre saúde, psicologia e educação. Mundo Saúde. 2012; 36(2):276-83 [citado 2018 Nov 7]. Disponível em: http:// bvsms.saude.gov.br/bvs/artigos/mundo_ saude/mutilacao_cancer_articulacoes_entre_ saude.pdf

Trabalho realizado na Universidade Federal do Rio Grande do Sul (UFRGS), Porto Alegre, RS, Brasil.

Conflito de interesses: As autoras declaram não haver.
29. Pini S, Hugh-Jones S, Gardner PH. What effect does a cancer diagnosis have on the educational engagement and school life of teenagers? A systematic review. Psychooncology. 2012;21(7):685-94 [citado 2019 Maio 12]. Disponível em: http://doi.wiley. com/10.1002/pon.2082

30. Thompson AL, Christiansen HL, Elam M, Hoag J, Irwin MK, Pao M, et al. Academic Continuity and School Reentry Support as a Standard of Care in Pediatric Oncology. Pediatr Blood Cancer. 2015;62 Suppl 5:S80517 [citado 2019 Maio 12]. Disponível em: http://doi.wiley.com/10.1002/pbc.25760

31. Helms AS, Schmiegelow $K$, Brok J, Johansen $C$, Thorsteinsson $T$, Simovska V, et al. Facilitation of school re-entry and peer acceptance of children with cancer: a review and meta-analysis of intervention studies. Eur J Cancer Care (Engl). 2016;25(1):1709 [citado 2019 Maio 12]. Disponível em: http://doi.wiley.com/10.1111/ecc.12230

32. Oliveira MR. Representações dos Barnabés em torno da experiência escolar durante e após a vivência da doença oncológica: um estudo exploratório [dissertação]. Braga: Universidade do Minho; 2017 [citado 2019 Maio 20]. Disponível em: https://repositorium. sdum.uminho.pt/handle/1822/51446

33. ABPp. Associação Brasileira de Psicopedagogia. Código de Ética do psicopedagogo [citado 2019 Maio 12]. Disponível em: https:// www.abpp.com.br/documentos_referencias_ codigo_etica.html

34. Piaget J. O possível e o necessário: evolução dos possíveis na criança. Volume 1. Porto Alegre: Artmed; 1985.

35. Piaget J. O possível e o necessário: evolução dos possíveis na criança. Volume 2. Porto Alegre: Artmed; 1986.

36. Piaget J. Estudos Sociológicos. Rio de Janeiro: Forense; 1973.

37. Montangero J, Maurice-Neville D. Piaget ou a inteligência em evolução. Porto Alegre: Artmed; 1998.

38. Piaget J. Psicologia e Pedagogia. Rio de Janeiro: Forense; 1970.

39. Kanemoto E, Petrilli AS, Covic NA, org. Implicações do câncer da criança no processo de alfabetização. Curitiba: Appris; 2020.

Artigo recebido: $13 / 10 / 2020$

Aprovado: 27/1/2021 